\title{
Physical illness and dementia among the elderly patients in a tertiary care hospital: a cross sectional study
}

\author{
Arman Ibne Haq, ${ }^{1}$ Mekhala Sarkar, ${ }^{2}$ Susmita Roy, ${ }^{3}$ Ahsan Uddin Ahmed ${ }^{4}$ \\ ${ }^{1}$ Registrar, Department of Psychiatry, Bangladesh Medical College, Dhaka, Bangladesh; ${ }^{2}$ Associate Professor, Department of \\ Psychotherapy, National Institute of Mental Health (NIMH), Sher-E-Bangla Nagar, Dhaka, Bangladesh; ${ }^{3}$ Associate Professor, \\ Department of Psychiatry, Jalalabad Ragib Rabeya Medical College, Sylhet, Bangladesh; ${ }^{4}$ Assistant Professor, Department of \\ Psychiatry, Shaheed Suhrawardy Medical College, Sher-E-Bangla Nagar, Dhaka, Bangladesh.
}

\begin{abstract}
Summary
Article info

Received

- 16 April, 2017

The elder people are rapidly increasing throughout the world and dementia has become the

Accepted

25 August, 2017

Number of tables : 05

Number of figures : 02

Number of refs : 24

important point of interest of health care professionals. The objective of the study was to find out

the physical illness and dementia as well as their association among the elderly patients. This was a cross sectional and analytical study conducted in National Institute of Mental Health (NIMH) at Sher-e-Bangla Nagar, Dhaka, Bangladesh during the period from $1^{\text {st }}$ November 2014 to $30^{\text {th }}$ April 2015 . For this purpose 78 elderly patients aged e" 60 years attending both in outpatient and inpatient department of NIMH satisfying inclusion and exclusion criteria, irrespective of age and gender were selected as study population by convenient sampling technique. The result showed that majority $(59 \%)$ had co-morbid physical illness. Common co-morbid physical illness was hypertension (26.9\%). Among the respondants, 5 (6.4\%) were current smokers and 12 $(15.38 \%)$ had past history of smoking for more than five years. In the study, $50 \%$ of the respondents diagnosed with dementia had hypertension $\left(c^{2}=3.8808, P=0.04884\right), 25 \%$ dementia patient had co-morbid diabetes mellitus $\left(c^{2}=2.4287, P=0.11913\right)$, history of cerebro vascular accident (CVA) was present in $25 \%$ of patient and $25 \%$ patient had history of smoking $\left(c^{2}=0.0088, P=\right.$ 0.92533). This study provided baseline information about clinical factors associated with dementic patients in Bangladesh which could be used in future studies.
\end{abstract}

Bang J Psychiatry 2017;31(1): 20-23

\section{Introduction}

Dementia is one of the major causes of morbidity in the elderly population. Although it is common after the age of 65 years, it can occur before the age of 65 years. ${ }^{1}$ Dementia is defined as a syndrome associated with range of diseases which are characterized by the progressive impairment of brain functions, including memory, language, perception, personality and cognitive skills. ${ }^{2}$ World Health Organization (WHO) estimated that 35.6 million people worldwide were living with dementia in $2010 .^{3}$ The common causes of dementia include Alzheimer's disease, vascular dementia, Lewy body dementia, fronto-temporal dementia, traumatic brain injury, substance, Parkinson's disease etc. ${ }^{4}$ Age, gender, smoking, hypertension, diabetes mellitus, dyslipidemia, head trauma, depression and genetic factors are considered as risk factors for dementia. ${ }^{5}$

The prevalence of dementia is approximately $5 \%$ in general population older than 65 years of age, $20-40 \%$ in general population older than 85 years, $15-20 \%$ in outpatient general medical practices and $50 \%$ in chronic care facilities. ${ }^{6}$ Dementia has been identified as one of the major causes of disability in later life. It accounts for $11.9 \%$ of the years lived with disability due to a non-communicable disease. ${ }^{7}$ Dementia is associated with increased mortality rate. Several studies have shown that people with dementia have markedly decreased survival rate than people without dementia. ${ }^{8-10}$ Among all chronic diseases, dementia makes the largest single contribution to disability and needs for care among older people. ${ }^{11}$ In Bangladesh, there is almost no data on different variables of dementia due to absence of epidemiological studies. With the world's eighth largest population with 160 million people, the percentage of people aged more than 60 years in Bangladesh is projected to increase to $9 \%$ by 2025 and $21 \%$ by 2050 . It is estimated that the number of people with dementia will be $4,60,000$ by 2015 and $8,34,000$ by 2025 and $21,93,000$ by $2050 .^{12}$

Considering the above mentioned facts on the dearth of data on dementia in Bangladesh and its huge importance have impelled the author to take on the study. The objective of the study was to find out the physical illness and dementia as well as their association among the elderly patients. 


\section{Materials and methods}

This descriptive cross sectional study was conducted in National Institute of Mental Health (NIMH) at Sher-e-Bangla Nagar, Dhaka, Bangladesh during the period from $1^{\text {st }}$ November 2014 to $30^{\text {th }}$ April 2015. For this purpose 78 elderly patients aged e"60 years attending both in outpatient and inpatient department of $\mathrm{NIMH}$ satisfying inclusion and exclusion criteria, irrespective of age and gender were selected as study population by convenient sampling technique. Patients with acute confusional state, acute physical illness and severe visual or hearing impairment were not included in this study. Informed consent was taken from each patient before enrollment in this study. Ethical issues were maintained properly. The respondents were interviewed face to face using a structured questionnaire containing information like type of service, physical illness, duration of physical illness, smoking etc. Cognitive impairment was assessed by Bangla version of mini mental state examination (MMSE) and dementia was diagnosed according to Diagnostic and Statistical Manual of Mental Disorder (DSM 5). ${ }^{13}$ The interviews were held in a peaceful and non-threatening environment. After collecting data, editing was done manually and was analyzed with the help of Statistical Package for the Social Sciences (SPSS) software package version 16

\section{Results}

A total of 78 respondents, $10.2 \%$ were selected from the inpatient department and $89.7 \%$ were from the outpatient department. Majority of the male (88.6\%) and female $(91.2 \%)$ were taken from outpatient department (Table 1). Most (59\%) of the respondents had physical illnesses (Figure 1). Among the group suffering from physical illness, 20 (43.5\%) patients had been suffering for 5 to 10 years and $16(34.8 \%)$ patients had been suffering for less than 5 years (Figure 2). In the present study, the common physical conditions were hypertension (26.9\%), cataract (19.57\%), diabetes mellitus (10.87\%) and ischemic heart disease $(10.87 \%$ ) (Table 2). Among the respondents 5 (6.4\%) were current smokers and $12(15.38 \%)$ had past history of smoking for more than five years (Table 3 ). One (25\%) patient had history of smoking ( $c^{2}=0.0088, P=0.92533$ ) (Table 4). Only $4(5.1 \%)$ were diagnosed as dementia among the respondants whose MMSE score were d"23. Two (50\%) of the respondents diagnosed with dementia had hypertension $\left(c^{2}=3.8808, p=\right.$ $0.04884)$. One (25\%) dementic patient had co-morbid diabetes mellitus ( $c^{2}=2.4287, p=0.11913$ ) and history of cerebro vascular accident (CVA) was present in one (25\%) patient (Table 5).

Table 1: Distribution of respondents according to types of service received $(n=78)$

\begin{tabular}{lccc}
\hline Types of service & $\begin{array}{c}\text { Male } \\
\text { Number (\%) }\end{array}$ & $\begin{array}{c}\text { Female } \\
\text { Number (\%) }\end{array}$ & $\begin{array}{c}\text { Total } \\
\text { Number (\%) }\end{array}$ \\
\hline Outpatient service & $39(88.6)$ & $31(91.2)$ & $70(89.7)$ \\
Inpatient service & $5(11.4)$ & $3(8.8)$ & $8(10.3)$ \\
\hline
\end{tabular}

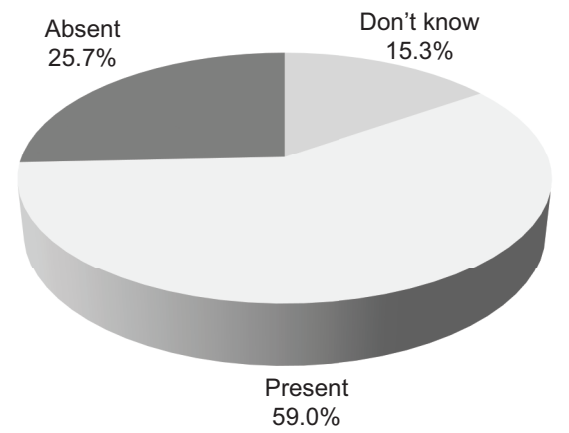

Figure 1: Presence of physical illnesses $(n=78)$

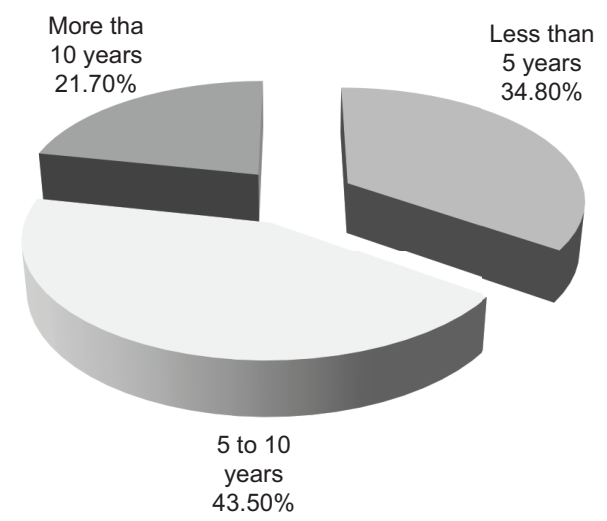

Figure 2: Duration of physical illness $(n=46)$

Table 2: Types of physical illness $(n=46)$

\begin{tabular}{|c|c|c|c|}
\hline Types of physical illness & Male & Female & Total \\
\hline Hypertension & $7(25.9 \%)$ & $5(26.3 \%)$ & $12(26.1 \%)$ \\
\hline Diabetes mellitus & $3(11.1 \%)$ & $2(10.5 \%)$ & $5(10.8 \%)$ \\
\hline Cataract & $5(18.5 \%)$ & $5(26.3 \%)$ & $10(21.7 \%)$ \\
\hline $\begin{array}{l}\text { Chronic obstructive } \\
\text { pulmonary disease }\end{array}$ & $2(7.4 \%)$ & $1(5.2 \%)$ & $3(6.5 \%)$ \\
\hline Ischemic heart disease & $4(14.8 \%)$ & $1(5.2 \%)$ & $5(10.8 \%)$ \\
\hline Rheumatological disorders & $1(3.7 \%)$ & $2(5.3 \%)$ & $3(6.5 \%)$ \\
\hline Urological disorders & $3(11.1 \%)$ & $0(0 \%)$ & $3(6.5 \%)$ \\
\hline CVA & $1(3.7 \%)$ & $1(5.2 \%)$ & $2(4.4 \%)$ \\
\hline Anemia & $0(0 \%)$ & $2(5.3 \%)$ & $2(4.4 \%)$ \\
\hline Parkinson's disease & $1(3.7 \%)$ & $0(0 \%)$ & $1(3.7 \%)$ \\
\hline Total & $27(100 \%)$ & $19(100 \%)$ & $46(100 \%)$ \\
\hline
\end{tabular}

Table 3: History of smoking of the respondants $(n=78)$

\begin{tabular}{lcc}
\hline History of smoking & Frequency & Percentage \\
\hline Absent & 61 & 78.2 \\
Current smoker & 5 & 6.4 \\
Past smoker & 12 & 15.4 \\
\hline
\end{tabular}


Table 4: Association between smoking with dementia $(n=78)$

\begin{tabular}{lccc}
\hline Smoking & $\begin{array}{c}\text { No dementia } \\
(\mathrm{n}=4)\end{array}$ & $\begin{array}{c}\text { Dementia } \\
(\mathrm{n}=4)\end{array}$ & p value \\
\hline No & $57(77.02 \%)$ & $3(75 \%)$ & $\chi^{2}=0.0088$ \\
Yes & $17(22.9 \%)$ & $1(25 \%)$ & $p=0.92533$ \\
\hline
\end{tabular}

Table 5: Association between physical illness with dementia $(n=78)$

\begin{tabular}{lccc}
\hline Physical illness & $\begin{array}{c}\text { No dementia } \\
(n=74)\end{array}$ & $\begin{array}{c}\text { Dementia } \\
(n=4)\end{array}$ & $p$ value \\
\hline Hypertension & & & \\
No & $64(86.4 \%)$ & $2(50 \%)$ & $c^{2}=3.8808$ \\
Yes & $10(21.7 \%)$ & $2(50 \%)$ & $p=0.04884$ \\
Diabetes mellitus & & & \\
No & $70(94.5 \%)$ & $3(75 \%)$ & $c^{2}=2.4287$ \\
Yes & $4(5.4 \%)$ & $1(25 \%)$ & $p=0.11913$ \\
CVA & & & \\
No & $73(98.6 \%)$ & $3(75 \%)$ & $c^{2}=8.4948$ \\
Yes & $1(1.3 \%)$ & $1(25 \%)$ & $p=0.00356$ \\
Ischemic heart disease & & \\
No & $69(93.2 \%)$ & $4(100 \%)$ & $c^{2}=0.2888$ \\
Yes & $5(6.7 \%)$ & $0(0 \%)$ & $p=0.59100$ \\
Rheumatological disorders & & \\
No & $71(95.9 \%)$ & $4(100 \%)$ & $c^{2}=0.1686$ \\
Yes & $3(4.0 \%)$ & $0(0 \%)$ & $p=0.68132$ \\
\hline
\end{tabular}

\section{Discussion}

In the present study, $59.8 \%$ of the respondents had known physical illness. The common physical illnesses were hypertension $(26.9 \%)$, cataract $(19.57 \%)$, diabetes mellitus $(10.87 \%)$ and ischemic heart disease $(10.87 \%)$. Two (50\%) older person with dementia in this study had hypertension and it was found to be significant $\left(c^{2}=3.8808, p=0.048\right)$. Diabetes mellitus was present in one (25\%) dementia patient. A Spanish study found that hypertension and diabetes were the comorbidities most frequently found in older people with dementia. ${ }^{14}$ Although, the analysis revealed these conditions as frequent in older people in general, there were some other conditions that appeared to be significantly associated with dementia like Parkinson's disease, congestive heart failure, cerebrovascular disease, osteoporosis, insomnia etc. Other international studies had similar results. ${ }^{15,16}$

In other hand hypertension had been associated with a wide variety of cognitive deficits, including reduced abstract reasoning (executive dysfunction), impaired memory, attention deficit, and slowing of mental processing speed. Some longitudinal studies also revealed that, individuals who developed dementia had a history of high blood pressure earlier in life. ${ }^{17-19}$ Type 2 diabetes had consistently been shown to be associated with increased risk for dementia. ${ }^{20}$ Majority of the previous studies showed a higher rate or risk for cognitive decline in diabetic subjects compared with non-diabetic subjects but some showed no association between the rate of cognitive deterioration and diabetes status. ${ }^{21-23}$ Differences between studies might be attributed to the cognitive status and age range of subjects included, as well as to the tools used to measure cognitive status and the definition of cognitive decline. ${ }^{22}$ These differences also reflected different roles for diabetes as a risk factor for dementia and in the rate of disease progression.

In current study, among the respondants, 5 (6.4\%) were current smokers and $12(15.38 \%)$ had past history of smoking for more than five years. $25 \%$ patients had history of smoking among dementia $\left(c^{2}=0.0088, p=0.92533\right)$. In this regard with environmental tobacco smoke exposure, the increased risk of dementia was found in a previous study. ${ }^{24}$

\section{Conclusion}

Despite a number of limitations, this study provides baseline information about physical illness associated with dementia among elderly patients in Bangladesh. When assessing an elderly patient, the presence of dementia should always be taken into consideration and more efforts should be given in the assessment and management of this disorder.

\section{References}

1. Larson EB, Yaffe K, Langa KM. New insights into the dementia epidemic. New Eng J Med 2013;369:2275-7.

2. Australian Institute of Health and Welfare. The impact of dementia on the health and aged care systems. Canberra: Australian Institute of Health and Welfare;2004.

3. World Health Organization. Dementia: a public health priority. Geneva: World Health Organization;2012.

4. Cowen P, Harrison P, Burns T, editors. Shorter Oxford textbook of Psychiatry. 6 $6^{\text {th }}$ ed. Oxford: Oxford University Press;2012. p. 321-5.

5. Catriona D, McCullagh C, Craig D, Mcilroy SP, Passmore AP. Risk factors for dementia. Adv Psychiatr Treat 2001;7: 24-31.

6. Sadock BJ, Sadock VA, editors. Kaplan and Sadock's synopsis of Psychiatry: behavioral sciences/clinical Psychiatry. 10 $0^{\text {th }}$ ed. Philadelphia: Lippincott, Williams and Wilkins;2007. p. 329-44.

7. World Health Organization. The global burden of disease: 2004 update. Geneva: World Health Organization;2008.

8. Waring SC, Doody RS, Pavlik VN, Massman PJ, Chan W. Survival among patients with dementia from a large multiethnic population. Alzheimer Dis Assoc Disord 2005;19(4):178-83.

9. Fitzpatrick AL, Kuller LH, Lopez OL, Kawas $\mathrm{CH}$, Jagust W. Survival following dementia onset; Alzheimer's disease and vascular dementia. J Neurol Sci 2005;229-30:43-9.

10. Freels S, Nyenhuis DL, Gorelick PB. Predictors of survival in African American patients with $A D, V a D$, stroke without dementia. Neurology 2002;59:1146-53. 
11. Alzheimer's Disease International. Policy brief for G8 heads of governments: the global impact of dementia 2013-2050. London: Alzheimer's Disease International;2013.

12. Das A, Samuel R, Patel V, Prince M, Parameshwaran R, Krishnamoorthy ES. The impact associated with caring for a person with dementia: a report from the 10/66 dementia research group's Indian network. Int J Geriatr Psychiatry 2004;19:182-4.

13. American Psychiatric Association. Diagnostic and statistical manual of mental disorders, $5^{\text {th }}$ ed. Arlington, VA: American Psychiatric Association;2013.

14. Poblador-Plou B, Calderón-Larrañaga A, Marta-Moreno J, Hancco-Saavedra J, Sicras-Mainar A, Soljak M, et al. Comorbidity of dementia: a cross-sectional study of primary care older patients. BMC Psychiatry 2014;14:84.

15. Bauer K, Schwarzkopf L, Graessel E, Holle R. A claims databased comparison of comorbidity in individuals with and without dementia. BMC Geriatrics 2014;14:10.

16. Löppönen MK, Isoaho RE, Räihä IJ, Vahlberg TJ, Loikas $\mathrm{SM}$, Takala TI, et al. Undiagnosed diseases in patients with Dementia - a potential target group for intervention. Dement Geriatr Cogn Disord 2004;18:321-9.

17. Elias MF, Goodell AL, Dore GA. Hypertension and cognitive functioning: a perspective in historical context. Hypertension 2012;60:260-8.
18. Waldstein SR, Manuck SB, Ryan CM, Muldoon MF. Neuropsychological correlates of hypertension: review and methodologic considerations. Psychol Bull 1991;110:45168.

19. Skoog I, Lernfelt B, Landahl S, Palmertz B, Andreasson LA, Nilsson L, et al. 15-year longitudinal study of blood pressure and dementia. Lancet 1996;347:1141-5.

20. Luchsinger JA. Adiposity, hyperinsulinemia, diabetes and Alzheimer's disease: an epidemiological perspective. Eur J Pharmacol 2008;585(1):119-29.

21. Xu W, Caracciolo B, Wang HX, Winblad B, Bäckman L, Qiu $C$, et al. Accelerated progression from mild cognitive impairment to dementia in people with diabetes. Diabetes 2010;59(11):2928-35.

22. Ravona-Springer R, Luo X, Schmeidler J, Wysocki M, Lesser G, Rapp M, et al. Diabetes is associated with increased rate of cognitive decline in questionably demented elderly. Dement Geriatr Cogn Disord 2010;29(1):68-74.

23. Van Den Berg E, de Craen AJ, Biessels GJ, Gussekloo J, Westendorp RG. The impact of diabetes mellitus on cognitive decline in the oldest of the old: a prospective population-based study. Diabetologia 2006;49(9):2015-23.

24. Chen R. Association of environmental tobacco smoke with dementia and Alzheimer's disease among never smokers. Alzheimers Dement 2012;8(6):590-5. 